\title{
Relationship between N-terminal pro-B-type natriuretic peptide and renal function: the effects on predicting early outcome after off-pump coronary artery bypass surgery
}

\author{
Youn Yi Jo ${ }^{1}$, Young Lan Kwak ${ }^{2,3}$, Jonghoon Lee ${ }^{2}$, and Yong Seon Choi ${ }^{2,3}$ \\ ${ }^{1}$ Department of Anesthesiology and Pain Medicine, Gachon University of Medicine and Science Gil Medical Center, Incheon, \\ ${ }^{2}$ Department of Anesthesiology and Pain Medicine and ${ }^{3}$ Anesthesia and Pain Research Institute, Yonsei University College of \\ Medicine, Seoul, Korea
}

Background: Plasma levels of N-terminal pro-B-type natriuretic peptide (NT-proBNP) provide useful prognostic predictors in patients after cardiac surgery. However, predictive accuracy of NT-proBNP levels has varied significantly according to renal dysfunction. The purpose of this study was to assess whether preoperative NT-proBNP levels could be used as predictors of early postoperative outcomes on the basis of renal function in patients undergoing off-pump coronary artery bypass surgery (OPCAB).

Methods: In 219 patients undergoing elective OPCAB, NT-proBNP and an estimated glomerular filtration rate (eGFR) were assessed preoperatively. All patients were divided into 3 groups according to tertiles of eGFR: the first (eGFR $\geq$ $\left.90 \mathrm{ml} / \mathrm{min} / 1.73 \mathrm{~m}^{2}\right)$, the second $\left(90 \mathrm{ml} / \mathrm{min} / 1.73 \mathrm{~m}^{2}>\right.$ eGFR $\geq 72 \mathrm{ml} / \mathrm{min} / 1.73 \mathrm{~m}^{2}$ ) and the third tertile group (eGFR $<72 \mathrm{ml} / \mathrm{min} / 1.73 \mathrm{~m}^{2}$ ). End point was the composite of early postoperative complications defined as myocardial infarction, new onset atrial fibrillation, ventricular dysfunction, prolonged mechanical ventilator care ( $>48 \mathrm{hr})$, prolonged ICU stay ( $\geq 3$ days), and in hospital mortality.

Results: There was no difference in early postoperative complications among groups. A preoperative NT-proBNP level of $228 \mathrm{pg} / \mathrm{ml}$ and $302 \mathrm{pg} / \mathrm{ml}$ (sensitivity 70\%, specificity 67\%, P $<0.001$ and sensitivity 73\%, specificity 63\%, P $=0.001$, respectively) were optimal cut-off values predicting complicated early postoperative course in second and third tertile group, respectively.

Conclusions: Preoperative NT-proBNP levels seem to be predictive of early postoperative complications in patients with eGFR $<90 \mathrm{ml} / \mathrm{min} / 1.73 \mathrm{~m}^{2}$ undergoing OPCAB. (Korean J Anesthesiol 2011; 61: 35-41)

Key Words: NT-proBNP, OPCAB, Renal function.

\footnotetext{
Received: October 15, 2010. Revised: 1st, November 10, 2010; 2nd, December 6, 2010. Accepted: December 27, 2010.

Corresponding author: Yong Seon Choi, M.D., Department of Anesthesiology and Pain Medicine and Anesthesia and Pain Research Institute, Yonsei University College of Medicine, 250, Seongsan-no, Seodaemun-gu, Seoul 120-752, Korea. Tel: 82-2-2228-8518, Fax: 82-2-364-2951, E-mail: yschoi@yuhs.ac

() This is an open-access article distributed under the terms of the Creative Commons Attribution Non-Commercial License (http:// creativecommons.org/licenses/by-nc/3.0/), which permits unrestricted non-commercial use, distribution, and reproduction in any medium, provided the original work is properly cited.
} 


\section{Introduction}

Off-pump coronary artery bypass surgery (OPCAB) has been widely used even in high-risk patients. However, displacement of the heart and occlusion of native coronary arteries may lead to ischemia and hemodynamic instability, resulting in potential postoperative complications despite the reported benefits of OPCAB without cardiopulmonary bypass [1-3]. Biomarkers that could predict patients at high risk of early postoperative course, either alone or in combination with existing clinical scoring systems, would be of considerable value to anesthesiologists.

Plasma levels of N-terminal pro-B-type natriuretic peptide (NT-proBNP) provide useful prognostic predictors not only in patients with congestive heart failure or acute coronary syndrome, but also in patients who underwent cardiac surgery [4-6]. In addition, preoperative plasma levels of NT-proBNP have been reported to be predictive for early postoperative cardiovascular complications in patients following OPCAB [5]. However, predictive accuracies of NT-proBNP levels have varied significantly according to multiple clinical factors including cardiac systolic and diastolic dysfunction, age, and renal dysfunction [7-11]. Subclassification on the basis of these factors, especially renal function, which has been shown to be a major determinant of plasma NT-proBNP levels, might improve predictive accuracies of NT-proBNP based prediction of early postoperative complications. However, there are limited studies on the predictive utility of plasma NT-proBNP levels according to preoperative renal function for postoperative cardiovascular morbidity in patients after cardiac surgery $[6,7]$.

The purpose of this study was to assess whether preoperative NT-proBNP levels could be used as prognostic predictors for early postoperative outcomes on the basis of renal function in patients following OPCAB.

\section{Materials and Methods}

After obtaining Institutional Review Board approval, a total of 219 consecutive patients scheduled for elective OPCAB from January 2008 to June 2010 were enrolled in this prospective observational study after screening for the following exclusion criteria: history of myocardial infarction (MI) within 1 week, significant valvular heart disease, emergency operation, prior cardiac surgery, age $<20$ years, and/or renal failure requiring dialysis. All patients were divided into 3 groups according to tertiles of preoperative estimated glomerular filtration rate (eGFR) using the Modification of Diet in Renal Disease equation [12]: the first $\left(e G F R \geq 90 \mathrm{ml} / \mathrm{min} / 1.73 \mathrm{~m}^{2}\right)$, the second $(90 \mathrm{ml} /$ $\mathrm{min} / 1.73 \mathrm{~m}^{2}>\mathrm{eGFR} \geq 72 \mathrm{ml} / \mathrm{min} / 1.73 \mathrm{~m}^{2}$ ) and the third tertile group (eGFR $<72 \mathrm{ml} / \mathrm{min} / 1.73 \mathrm{~m}^{2}$ ).

Preoperative patients' characteristics, including age, gender, body mass index, New York Heart Association functional classification [13], recent MI, diabetes mellitus, cerebrovascular attack, arterial hypertension, chronic obstructive pulmonary disease, left ventricular ejection fraction, EuroSCORE (European System for Cardiac Operative Risk Evaluation) [14] and medications, were assessed.

\section{Anesthesia and surgical technique}

All patients received 0.05 to $0.1 \mathrm{mg} / \mathrm{kg}$ of morphine intramuscularly as premedication 1 hour before the operation. On arrival in the operating room, standard monitoring, such as lead II and V5 of ECG, arterial blood pressure, pulse-oxymetry, bispectral index and cerebral oxymetry, were applied with a pulmonary artery catheter (Swan-Ganz CCOmbo CCO/ $\mathrm{SvO}_{2}{ }^{\mathrm{TM}}$, Edwards Lifesciences LLC, Irvine, CA, USA) inserted in the right internal jugular vein. Anesthesia was induced with intravenous midazolam (0.03-0.07 mg/ $\mathrm{kg}$ ), sufentanil $(1.5-3.0 \mu \mathrm{g} / \mathrm{kg}$ ) and rocuronium bromide $50 \mathrm{mg}$ and then maintained with sevoflurane $(0.4-1.5 \%)$, sufentanil $(0.5-1.5$ $\mu \mathrm{g} / \mathrm{kg} / \mathrm{min}$ ) and vecuronium $(1-2 \mu \mathrm{g} / \mathrm{kg} / \mathrm{min})$. Intravascular volume replacement was managed with crystalloid and colloid solutions to maintain the pulmonary capillary wedge pressure (PCWP) between 8 and $14 \mathrm{mmHg}$ according to baseline values before enucleation of the heart and before volume status that was evaluated by intraoperative trans-esophageal echocardiography. Central blood temperature measured by the pulmonary artery catheter was maintained at approximately $36^{\circ} \mathrm{C}$ with a warm mattress, forced warm air blanket and fluid warmer, as necessary. During the surgical procedure, mean arterial pressure (MAP) was maintained above $70 \mathrm{mmHg}$ either with a $10^{\circ}$ to $20^{\circ}$ Trendelenburg position and/or norepinephrine infusion. To expose and stabilize the target coronary vessel, posterior pericardial stitch, large gauze $(12 \times 70 \mathrm{~cm})$ swabs, and tissue stabilizer (Octopus Tissue Stabilization System ${ }^{\circledR}$, Medtronic Inc. Minneapolis, MN, USA) were used. Allogenicpacked red blood cells were transfused when the hematocrit level was $<25 \%$ throughout the study period. All patients were transferred to the intensive care unit (ICU) after surgery.

\section{Postoperative management}

All patients received standardized ICU care at the discretion of ICU staff (cardiothoracic surgeons and anesthetists) blinded to this study according to the standard ICU protocols of our institution. Criteria for weaning from ventilatory support included an appropriate sensorium, hemodynamic stability (cardiac index > $2.2 \mathrm{~L} / \mathrm{min} / \mathrm{m}^{2}$; MAP > $60 \mathrm{mmHg}$; PCWP < $20 \mathrm{mmHg}$; and no significant arrhythmias), $\mathrm{PaO}_{2} / \mathrm{FiO}_{2}>200$, minimal chest tube drainage, urine output $>0.5 \mathrm{ml} / \mathrm{kg} / \mathrm{h}$, 
and temperature $>35.5^{\circ} \mathrm{C}$. Discharging criteria from the ICU were as follows: stabilized patient's clinical status without the need for ICU monitoring and care (which included no further requirement for either inotropic or vasoactive agents), and no plan for further active intervention.

End point was the composite of early postoperative complications defined as MI, new onset atrial fibrillation, ventricular dysfunction, prolonged mechanical ventilator care $(>48$ hr), prolonged ICU stay ( $\geq 3$ days), and mortality during hospitalization. Postoperative MI was defined as an increase in troponin- $\mathrm{T} \geq 0.5 \mathrm{ng} / \mathrm{ml}$ ( 5 times above the upper normal limit) and a development of new pathologic $Q$ wave or a new left bundle branch block [14]. Ventricular dysfunction was defined as the requirement for inotropes, new intra-aortic balloon pump or ventricular assist device support after OPCAB.

NT-proBNP was analyzed from routinely assessed blood samples one day before surgery and on postoperative day 7 . Preoperative NT-proBNP concentrations were measured with electrochemiluminescence immunoassay using the Elecsys analyzer (Elecsys proBNP, Roche Diagnostics GmbH, Basel, Switzerland) one day before surgery. Creatine kinase-CK$\mathrm{MB}$ and troponin-T were also assessed before surgery and on postoperative days 1 and 2 .

\section{Statistical analysis}

Continuous variables were shown as mean $\pm \mathrm{SD}$, and categorical variables were shown as a number (\%). To compare each group, $\chi^{2} /$ Fisher exact tests for categorical variables and one-way ANOVA for continuous variables were used as appropriate. To evaluate the utility of NT-proBNP as a prognostic indicator of postoperative cardiac morbidity and prolonged ICU stay, receiver operating characteristic (ROC) curves were calculated in all patients and in each tertile group of patients. All analysis was performed with SPSS 17.0 (SPSS Inc., Chicago, IL, USA). In all tests, a P value of $<0.05$ was considered as statistically significant.

\section{Results}

OPCAB was performed successfully in all 219 patients. Patient characteristics and preoperative data according to preoperative renal function are shown in Table 1 . There were no significant differences among groups, except female gender, which was more frequent in the first tertile group than in the other groups $(\mathrm{P}<0.001)$. The EuroSCORE was $3.3 \pm 2.0$ in the first tertile group, $2.8 \pm 2.0$ in the second tertile group, and $3.2 \pm 1.8$ in the third tertile group $(\mathrm{P}=0.23)$.

There were no significant differences in cardiac morbidity and other postoperative outcomes among groups (Table 2). There was one patient classified as in-hospital mortality in the third tertile group. Postoperative NT-proBNP levels were 2,011 \pm $4,782 \mathrm{pg} / \mathrm{ml}$ in the first tertile group, $1,461 \pm 1,367 \mathrm{pg} / \mathrm{ml}$ in the second tertile group, and 2,035 $\pm 2,373 \mathrm{pg} / \mathrm{ml}$ in the third tertile

Table 1. Patient Characteristics

\begin{tabular}{|c|c|c|c|c|c|}
\hline & $\begin{array}{c}\text { Total } \\
(\mathrm{n}=219)\end{array}$ & $\begin{array}{c}1^{\text {st }} \text { tertile } \\
\text { eGFR } \geq 90 \\
(n=73)\end{array}$ & $\begin{array}{c}2^{\text {nd }} \text { tertile } \\
90>\text { eGFR } \geq 72 \\
(\mathrm{n}=73)\end{array}$ & $\begin{array}{c}3^{\text {rd }} \text { tertile } \\
\text { eGFR }<72 \\
(\mathrm{n}=73)\end{array}$ & $P$ value \\
\hline Age (years) & $66 \pm 7$ & $65 \pm 12$ & $65 \pm 8$ & $68 \pm 7$ & 0.07 \\
\hline Female gender & $71(32)$ & $44(60)$ & $16(22)$ & $11(15)$ & $<0.001$ \\
\hline BMI $\left(\mathrm{kg} / \mathrm{m}^{2}\right)$ & $24.4 \pm 3.0$ & $24.4 \pm 2.8$ & $24.3 \pm 3.3$ & $24.6 \pm 3.0$ & 0.66 \\
\hline NYHA III-IV & $40(18)$ & $11(15)$ & $16(22)$ & $13(18)$ & 0.12 \\
\hline Recent MI & $28(13)$ & $9(12)$ & $11(15)$ & $8(11)$ & 0.79 \\
\hline Diabetes mellitus & $89(41)$ & $26(36)$ & $31(42)$ & $32(44)$ & 0.46 \\
\hline CVA & $13(6)$ & $6(12)$ & $3(4)$ & $4(5)$ & 0.68 \\
\hline Hypertension & $131(60)$ & $39(53)$ & $42(57)$ & $50(68)$ & 0.06 \\
\hline COPD & $20(9)$ & $3(4)$ & $7(10)$ & $10(14)$ & 0.11 \\
\hline LVEF (\%) & $54 \pm 15$ & $59 \pm 14$ & $57 \pm 15$ & $55 \pm 15$ & 0.18 \\
\hline$<50 \%$ & $61(28)$ & $18(25)$ & $20(27)$ & $23(32)$ & 0.21 \\
\hline EuroSCORE & $3.1 \pm 1.9$ & $3.3 \pm 2.0$ & $2.8 \pm 2.0$ & $3.2 \pm 1.8$ & 0.23 \\
\hline NT-proBNP at baseline(pg/ml) & $1,102 \pm 2,962$ & $1,014 \pm 4,135$ & $1,061 \pm 1,908$ & $1,230 \pm 2,419$ & 0.98 \\
\hline Hemoglobin at baseline $(\mathrm{mg} / \mathrm{dl})$ & $13.1 \pm 1.1$ & $12.9 \pm 1.1$ & $13.0 \pm 1.1$ & $13.1 \pm 1.4$ & 0.92 \\
\hline \multicolumn{6}{|l|}{ Medications } \\
\hline$\beta$ blocker & $138(63)$ & $40(55)$ & $48(66)$ & $50(68)$ & 0.08 \\
\hline ССВ & $91(42)$ & $26(36)$ & $28(38)$ & $37(51)$ & 0.09 \\
\hline ACE inhibitor & $64(29)$ & $22(30)$ & $18(25)$ & $24(33)$ & 0.49 \\
\hline Statin & $99(45)$ & $37(51)$ & $30(41)$ & $32(44)$ & 0.53 \\
\hline
\end{tabular}

Data are expressed as mean \pm SD or number of patients (\%). eGFR: estimate glomerular filtration rate, BMI: body mass index, NYHA: New York heart association functional classification, Recent MI: myocardial infarction within 1 month, CVA: cerebrovascular attack, COPD: chronic obstructive pulmonary disease, LVEF: left ventricular ejection fraction, EuroSCORE: European system for cardiac operative risk evaluation, NTproBNP: N-terminal pro-B-type natriuretic peptide, CCB: calcium channel blocker, ACE inhibitor: angiotensin converting enzyme inhibitor. 
Table 2. Early Postoperative Complications and Length of ICU and Hospital Stay

\begin{tabular}{|c|c|c|c|c|c|}
\hline & $\begin{array}{c}\text { Total } \\
(\mathrm{n}=219)\end{array}$ & $\begin{array}{c}1^{\text {st }} \text { tertile } \\
\text { eGFR } \geq 90 \\
(n=73)\end{array}$ & $\begin{array}{c}2^{\text {nd }} \text { tertile } \\
90>\text { eGFR } \geq 72 \\
(\mathrm{n}=73)\end{array}$ & $\begin{array}{c}3^{\text {rd }} \text { tertile } \\
\text { eGFR }<72 \\
(n=73)\end{array}$ & $P$ value \\
\hline Total early postoperative complications & $106(48)$ & $33(45)$ & $32(44)$ & $41(56)$ & 0.26 \\
\hline Myocardial infarction & $12(5)$ & $4(5)$ & $4(5)$ & $4(5)$ & 1.0 \\
\hline Atrial fibrillation & $18(8)$ & $5(7)$ & $4(5)$ & $9(12)$ & 0.23 \\
\hline Ventricular dysfunction & $32(15)$ & $7(10)$ & $12(16)$ & $13(18)$ & 0.27 \\
\hline Mechanical ventilator $>48 \mathrm{hr}$ & $5(2)$ & $0(0)$ & $2(3)$ & $3(4)$ & 0.21 \\
\hline ICU stay $\geq 3$ days & $72(33)$ & $23(32)$ & $21(29)$ & $25(34)$ & 0.45 \\
\hline In-hospital mortality & $1(0)$ & $0(0)$ & $0(0)$ & $1(1)$ & 0.33 \\
\hline ICU stay (days) & $2.5 \pm 1.2$ & $2.4 \pm 0.7$ & $2.5 \pm 1.2$ & $2.7 \pm 1.5$ & 0.48 \\
\hline Length of hospital stay (days) & $15 \pm 12$ & $13 \pm 5$ & $14 \pm 6$ & $19 \pm 19$ & 0.30 \\
\hline
\end{tabular}

Data are expressed as mean \pm SD or number of patients (\%). eGFR: estimated glomerular filtration rate, ICU: intensive care unit.
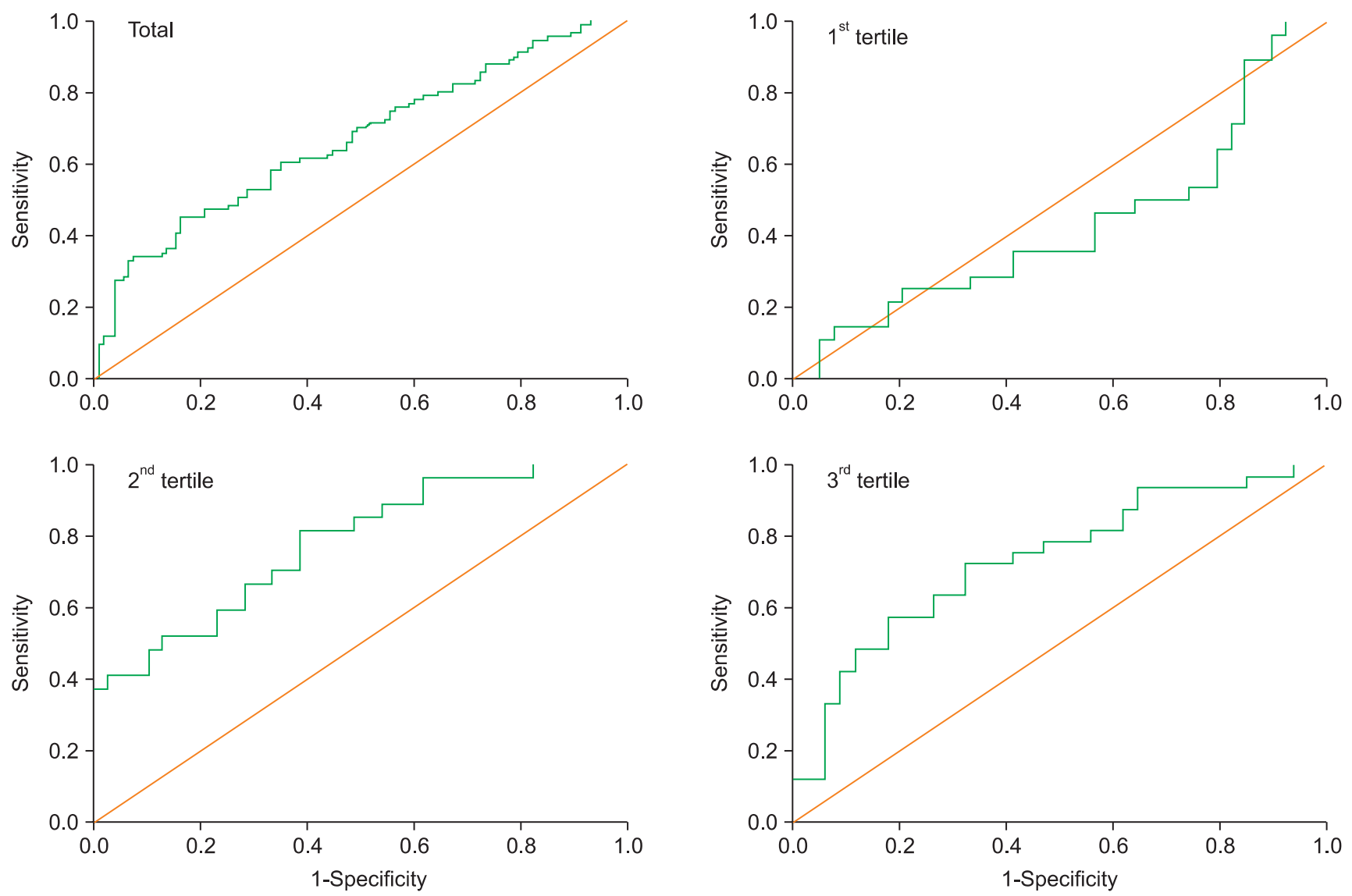

Fig. 1. The receiver operating characteristic curve about early postoperative complications of NT-proBNP.

group, and there was no significant difference among groups ( $\mathrm{P}$ $=0.613$ ).

Sensitivity and specificity for early postoperative complications were combined at different concentrations of NTproBNP by ROC analysis (Fig. 1). The area under curve (AUC) using preoperative NT-proBNP to detect early postoperative complications was $0.668(\mathrm{P}<0.001)$ in all patients, 0.429 in the first tertile group $(\mathrm{P}=0.321), 0.780$ in the second tertile group
(95\% CI, 0.668-0.892; $\mathrm{P}<0.001$ ), and 0.736 in the third tertile group (95\% CI, $0.616-0.856$; $\mathrm{P}=0.001$ ). A preoperative NTproBNP value of $228 \mathrm{pg} / \mathrm{ml}$ had a sensitivity of $70 \%$, specificity of $67 \%$, and accuracy of $68 \%$ in the second tertile group, and $302 \mathrm{pg} / \mathrm{ml}$ had a sensitivity of $73 \%$, specificity of $63 \%$, and accuracy of $66 \%$ in the third tertile group for predicting early postoperative complications (Table 3). The mean NTproBNP levels were significantly higher in patients with early 
Table 3. Values of NT-proBNP Receiver Operating Characteristic Curve for Early Postoperative Complications

\begin{tabular}{lcccc}
\hline & $\begin{array}{c}\text { Total } \\
(\mathrm{n}=219)\end{array}$ & $\begin{array}{c}1^{\text {st }} \text { tertile } \\
\text { eGFR } \geq 90 \\
(\mathrm{n}=73)\end{array}$ & $\begin{array}{c}2^{\text {nd }} \text { tertile } \\
90>\text { eGFR } \geq 72 \\
(\mathrm{n}=73)\end{array}$ & $\begin{array}{c}3^{\text {rd }} \text { tertile } \\
\text { eGFR }<72 \\
(\mathrm{n}=73)\end{array}$ \\
\hline Cut-off value (pg/ml) & 274 & 172 & 228 & 302 \\
Sensitivity (\%) & 62 & 51 & 70 & 73 \\
Specificity (\%) & 62 & 43 & 67 & 63 \\
PPV (\%) & 62 & 48 & 69 & 66 \\
NPV (\%) & 62 & 47 & 0.780 & 0.736 \\
AUC & 0.668 & 0.429 & 0.000 & 0.001 \\
Significance & 0.000 & 0.321 & $0.668-0.892$ & $0.616-0.856$ \\
95\% CI & $0.593-0.743$ & $0.285-0.572$ & \\
\hline
\end{tabular}

eGFR: estimated glomerular filtration rate, NT-proBNP: N-terminal pro brain natriuretic peptide, PPV: positive predictive value, NPV: negative predictive value, AUC: area under curve, $95 \%$ CI: $95 \%$ confidence interval.

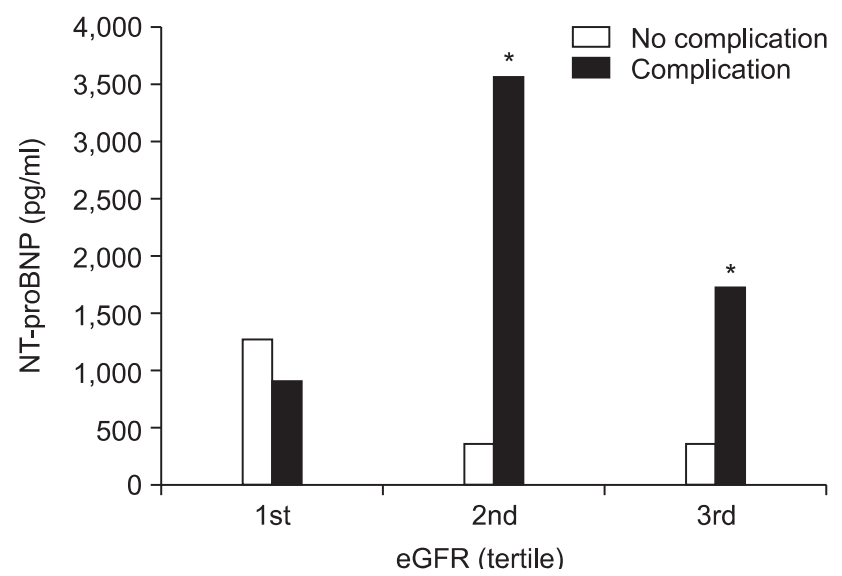

Fig. 2. Mean values of NT-proBNP in each tertile groups. abbreviation: no complication, no early postoperative complications; complication, early postoperative complication. ${ }^{*} \mathrm{P}<0.05$ compared with No complication.

postoperative complications in the second $(\mathrm{P}=0.002)$ and third $(\mathrm{P}=0.01)$ tertile groups (Fig. 2).

\section{Discussion}

This study was designed to examine the predictive value of plasma levels of NT-proBNP for early postoperative complications after OPCAB by subclassification according to preoperative renal function. We found that preoperative levels of NT-proBNP seemed to predict early postoperative course in patients with eGFR $<90 \mathrm{ml} / \mathrm{min} / 1.73 \mathrm{~m}^{2}$ following OPCAB. However, plasma NT-proBNP levels were not a reliable predictor for early postoperative outcomes in patients with eGFR $\geq 90 \mathrm{ml} /$ $\mathrm{min} / 1.73 \mathrm{~m}^{2}$; therefore, predictive tools combined with clinical scoring systems might be needed in this population.

Numerous risk indices have been developed in an attempt to predict postoperative morbidity and mortality in patients undergoing cardiac surgery. Although these indices have been actively studied, they have been found to have questionable predictive value, accuracy, and overall usability in a clinical setting [15-19]. The prognostic value of NT-proBNP has been demonstrated in patients with congestive heart failure and acute coronary syndrome [20]. Preoperative plasma levels of NTproBNP are also known to predict adverse outcomes after the cardiac surgery, even after OPCAB without cardiopulmonary bypass $[6,20,21]$. However, plasma levels of NT-proBNP are affected by multiple factors such as age, cardiac systolic and diastolic dysfunction, blood hemoglobin concentration, and renal dysfunction [7-11]. Therefore, subclassification on the basis of preoperative renal function might improve predictive accuracies of NT-proBNP for prediction of postoperative morbidity and mortality. There are, however, only limited data regarding their predictive accuracies for postoperative outcomes after cardiac and noncardiac vascular surgery $[6,8,22]$.

Our results demonstrated that NT-proBNP was valuable in predicting early postoperative complications only in patients with eGFR $<90 \mathrm{ml} / \mathrm{min} / 1.73 \mathrm{~m}^{2}$ undergoing OPCAB. Natriuretic peptides are produced in the myocardium in response to myocyte stretch, mainly due to pressure or volume overload, and subsequently split into BNP and NT-proBNP. Plasma NT-proBNP, which is biologically inactive and has a longer half-life than that of BNP (60-120 min vs. $20 \mathrm{~min})$, is cleared by the kidneys; thus, renal function has been shown to be a major determinant of plasma NT-proBNP level $[7,9]$. Agerelated elevation of BNP has also been reported to be partially due to renal functional changes [10]. In patients with chronic kidney disease not requiring dialysis and without cardiac symptoms, NT-proBNP level elevation has been reported to reflect underlying coronary disease and left ventricular hypertrophy independent of renal function [23]. In addition, NT-proBNP concentrations were also independently associated with mortality in hemodialysis patients [24]. However, in patients undergoing noncardiac vascular surgery regardless of underlying cardiac disease, the prognostic value of NT-proBNP 
for cardiac outcomes was useful only in patients with GFR $\geq 30$ $\mathrm{ml} / \mathrm{min} / 1.73 \mathrm{~m}^{2}$, most pronounced in patients with $\mathrm{GFR} \geq 90$ $\mathrm{ml} / \mathrm{min} / 1.73 \mathrm{~m}^{2}$, but not as useful in patients with GFR $<30 \mathrm{ml} /$ $\min / 1.73 \mathrm{~m}^{2}$ [8]. In our study, the discriminative value of NTproBNP was useful in patients with eGFR $<90 \mathrm{ml} / \mathrm{min} / 1.73 \mathrm{~m}^{2}$. In comparison to a previous study [8], we could not evaluate the influence of extremely reduced renal function on the usefulness of NT-proBNP as a prognostic cardiac risk marker because there were only 3 patients with $\mathrm{eGFR}<30 \mathrm{ml} / \mathrm{min} / 1.73 \mathrm{~m}^{2}$. In addition, underlying coronary disease and decreased cardiac systolic function might affect the discrepancy between previous studies and our results in patients with GFR $\geq 90 \mathrm{ml} / \mathrm{min} / 1.73$ $\mathrm{m}^{2}$. The inverse relationship between NT-proBNP and eGFR reflect not only reduced renal function, but also the presence of underlying coronary disease, heart failure, or plasma volume overload. Therefore, the optimal cut-off values and predictive accuracies of NT-proBNP according to preoperative renal function might be different between patients with cardiac disease and patients without cardiac disease.

There are some limitations in this study. This study had a small number of patients; therefore, results need to be confirmed in a larger sample population. Further study is also needed to find predictive values of NT-proBNP in patients with renal failure requiring dialysis and undergoing OPCAB, as this patient population was excluded from our study. In addition, it needs to be determined whether NT-proBNP combined with clinical scoring systems could better predict early outcomes after cardiac surgery in patients with GFR $\geq 90 \mathrm{ml} / \mathrm{min} / 1.73 \mathrm{~m}^{2}$.

In conclusion, preoperative NT-proBNP levels may be a potential predictive marker for early postoperative complications in patients who may require further hemodynamic optimization during the perioperative period, with eGFR under $90 \mathrm{ml} / \mathrm{min} / 1.73 \mathrm{~m}^{2}$ undergoing OPCAB.

\section{References}

1. Youn YN, Chang BC, Hong YS, Kwak YL, Yoo KJ. Early and midterm impacts of cardiopulmonary bypass on coronary artery bypass grafting in patients with poor left ventricular dysfunction: a propensity score analysis. Circ J 2007; 71: 1387-94.

2. Toumpoulis IK, Anagnostopoulos CE, DeRose JJ, Swistel DG. Early and mid-term outcome after off-pump coronary artery bypass grafting in patients with left ventricular dysfunction. Heart Surg Forum 2004; 7: E539-45.

3. Attaran S, Shaw M, Bond L, Pullan MD, Fabri BM. Does off-pump coronary artery revascularization improve the long-term survival in patients with ventricular dysfunction? Interact Cardiovasc Thorac Surg 2010; 11: 442-6.

4. Tsutamoto T, Wada A, Maeda K, Hisanaga T, Maeda Y, Fukai D, et al. Attenuation of compensation of endogenous cardiac natriuretic peptide system in chronic heart failure: prognostic role of plasma brain natriuretic peptide concentration in patients with chronic symptomatic left ventricular dysfunction. Circulation 1997; 96: 50916 .

5. Kerbaul F, Collart F, Giorgi R, Oddoze C, Lejeune PJ, Guidon C, et al. Increased plasma levels of pro-brain natriuretic peptide in patients with cardiovascular complications following off-pump coronary artery surgery. Intensive Care Med 2004; 30: 1799-806.

6. Cuthbertson BH, Croal BL, Rae D, Gibson PH, McNeilly JD, Jeffrey $\mathrm{RR}$, et al. N-terminal pro-B-type natriuretic peptide levels and early outcome after cardiac surgery: a prospective cohort study. Br J Anaesth 2009; 103: 647-53.

7. Choi EY, Ha JW, Joung B, Ko YG, Choi D, Rim SJ, et al. Effects of hemoglobin concentration and creatinine clearance in pro-B-type natriuretic peptide-based left ventricular filling pressure prediction in patients with preserved left ventricular systolic function. Am J Cardiol 2008; 101: 364-9.

8. Goei D, Schouten O, Boersma E, Welten GM, Dunkelgrun M, Lindemans J, et al. Influence of renal function on the usefulness of $\mathrm{N}$ terminal proB-type natriuretic peptide as a prognostic cardiac risk marker in patients undergoing noncardiac vascular surgery. Am J Cardiol 2008; 101: 122-6.

9. Tsutamoto T, Wada A, Sakai H, Ishikawa C, Tanaka T, Hayashi $\mathrm{M}$, et al. Relationship between renal function and plasma brain natriuretic peptide in patients with heart failure. J Am Coll Cardiol 2006; 47: 582-6.

10. Kawai K, Hata K, Tanaka K, Kubota Y, Inoue R, Masuda E, et al. Attenuation of biologic compensatory action of cardiac natriuretic peptide system with aging. Am J Cardiol 2004; 93: 719-23.

11. Bay M, Kirk V, Parner J, Hassager C, Nielsen H, Krogsgaard K, et al. NT-proBNP: a new diagnostic screening tool to differentiate between patients with normal and reduced left ventricular systolic function. Heart 2003; 89: 150-4.

12. Levey AS, Bosch JP, Lewis JB, Greene T, Rogers N, Roth D. A more accurate method to estimate glomerular filtration rate from serum creatinine: A new prediction equation. Ann Intern Med 1999; 130: 461-70.

13. The Criteria Committee of the New York Heart Association. Nomenclature and Criteria for Diagnosis of Diseases of the Heart and Great Vessels. 9th ed. Boston, Mass, Little, Brown \& Co. 1994, pp 253-6.

14. Nashef SA, Roques F, Michel P, Gauducheau E, Lemeshow S, Salamon R. European system for cardiac operative risk evaluation (EuroSCORE). Eur J Cardiothorac Surg 1999; 16: 9-13.

15. Dupuis JY, Wang F, Nathan H, Lam M, Grimes S, Bourke M. The cardiac anesthesia risk evaluation score: a clinically useful predictor of mortality and morbidity after cardiac surgery. Anesthesiology 2001; 94: 194-204.

16. Weightman WM, Gibbs NM, Sheminant MR, Thackray NM, Newman MA. Risk prediction in coronary artery surgery: a comparison of four risk scores. Med J Aust 1997; 166: 408-11.

17. Martinez-Alario J, Tuesta ID, Plasencia E, Santana M, Mora ML. Mortality prediction in cardiac surgery patients: comparative performance of Parsonnet and general severity systems. Circulation 1999; 99: 2378-82.

18. Pons JM, Espinas JA, Borras JM, Moreno V, Martin I, Granados A. Cardiac surgical mortality: comparison among different additive 
risk scoring models in a multicenter sample. Arch Surg 1998; 133: 1053-7.

19. Orr RK, Maini BS, Sottile FD, Dumas EM, O'Mara P. A comparison of four severity-adjusted models to predict mortality after coronary artery bypass graft surgery. Arch Surg 1995; 130: 301-6.

20. Cuthbertson BH, Mc Keown A, Croal BL, Mutch WJ, Hillis GS. Utility of B-type natriuretic peptide in patients with cardiovascular complications following off-pump coronary artery surgery. Br J Anaesth 2007; 99: 170-6.

21. Hutfless R, Kazanegra R, Madani M, Bhalla MA, Tulua-Tata A, Chen A, et al. Utility of B-type natriuretic peptide in predicting postoperative complications and outcomes in patients undergoing heart surgery. J Am Coll Cardiol 2004; 43: 1873-9.
22. Pfister R, Diedrichs H, Schiedermair A, Rosenkranz S, Hellmich M, Erdmann E, et al. Prognostic impact of NT-proBNP and renal function in comparison to contemporary multi-marker risk scores in heart failure patients. Eur J Heart Fail 2008; 10: 315-20.

23. DeFilippi CR, Fink JC, Nass CM, Chen H, Christenson R. N-terminal pro-B-type natriuretic peptide for predicting coronary disease and left ventricular hypertrophy in asymptomatic CKD not requiring dialysis. Am J Kidney Dis 2005; 46: 35-44.

24. Gutiérrez OM, Tamez H, Bhan I, Zazra J, Tonelli M, Wolf M, et al. N-terminal pro-B-type natriuretic peptide (NT-proBNP) concentrations in hemodialysis patients: prognostic value of baseline and follow-up measurements. Clin Chem 2008; 54: 1339-48. 